\title{
The Meaning of Life as a Subject of Philosophical Reflection*
}

\author{
Sergey Lokhov \\ Peoples' Friendship University of Russia \\ Moscow, Russia \\ E-mail: lokhov_sa@rudn.university
}

\author{
Dmitry Mamchenkov \\ Peoples' Friendship University of Russia \\ Moscow, Russia \\ E-mail: mamchenkov_dv@rudn.university
}

\author{
Daria Tavberidze \\ Peoples' Friendship University of Russia \\ Moscow, Russia \\ E-mail: tavdaria@gmail.com
}

\begin{abstract}
The article concerns the meaning of life issue that has been a fundamental problem of philosophical reflection for ages. Every generation introduces own connotations to it. In modern culture, a tendency of spreading addictive forms of behavior is being observed, and, as a result, the formation of a "conceptual vacuum" around the problem of the meaning of life. On the other hand, in the postmodern world the problem of the meaning of life becomes more urgent than ever. In the paper, we consider the main meaning-of-life orientations and their philosophical justifications.
\end{abstract}

Keywords-meaning of life; human nature; value; freedom; duty; supreme good; ideal

\section{INTRODUCTION}

One of the unexplored aspects of modern culture is the growing trend of the formation of addictive (dependent) forms of personality behavior. Addiction is a serious disorder; it is almost impossible to cope with it independently without using someone's help. Alcoholism and drug addiction are the best known and the most destructive among them. However, now there are much more dangerous psychological addictions: the gaming, computer, sexual ones, social network addiction. Addictology is a science that studies dependent forms of behavior and identifies more than 200 kinds of them. At the heart of the "mechanism" for the formation of dependence is the escape from reality and the need to adopt a certain imaginary role. In the process of development of dependence in a person, the circle of interests becomes narrower, higher needs and the mindsets of the individual are pushed aside, the meaning-related sphere of personality is destroyed, and a "sense vacuum" is formed [1]. The problem of addiction acquires a mass character and emerges out of the zone of private interests and interpersonal relations. It is not just about the nation's health, but rather about its survival.

In addition to medical, social, economic, existential

*This work has been supported by the RUDN initiative grant No. 100412-0-000 "Science and Myth" causes, addiction has causes lying in the deep foundations of culture. The foundation of spiritual culture is a collection of knowledge, values, meanings, including the meaning of life, in which the goal-setting connections of the individual with the world are expressed [2]. The meanings of life are a rationalized form of the value attitude to the world, which actualizes the possibility of self-awareness, the person's construction of him/herself, of his/her life path. The meanings of life are powerful motivators of actions, on their basis a strategy of life behavior and a style of life are formed, and besides, they (together with ideas, concepts, theories and other rational forms of knowledge) carry out the function of "world understanding" [3]. The meaning of life cannot be presented in the form of fully substantiated knowledge. The meaning of life is assimilated in the process of socialization, with the development of language, stereotypes of behavior, traditions and beliefs, etc. Experience of life, its being filled with meaning (and even the experience of lack of meaning) is always individual [4]. The volatility of life circumstances periodically pushes people to rethink their life reference points. In this situation, a person essentially faces a philosophical problem; the individual life experience is not sufficient there. When we go to the level of philosophical comprehension of life, it turns out that there are not so many conceptions of the meaning of life. A huge variety of individual interpretations of the "meaning of life" can be reduced to six basic versions [5].

\section{THE RELIGIOUS MEANING OF LIFE}

In the most general sense, religion is the connection of the person to God. In any religion two components are mandatory. The first is the concept of God and the doctrine of posthumous existence (dogmatics); the second is the ritual part, a cult as a system of actions, rituals that ensure the person's stable connection with God. Religion forms a worldview in which the person and his/her "wants", are not the highest and only value, whereas power is not a universal regulator of the relationships between man and man (in all the diversity of their manifestations - social, political, 
economic, etc.) [6]. Religion, focusing attention on the transcendental timeless principles of Existence (theocentrism) offers higher ideals for the person, the aspiration towards which forms the integrity of the worldview, predetermines all other forms of activity and relationships. Religion gives a concrete and comprehensive answer to the question of the meaning and purpose of human life. The main characteristic of the religious concept of the meaning of life is its transcendental character.

The religious meaning of life has two aspects - positive and negative. The pursuit of perfection, the union with the absolute good (God) reveals the meaning of life in its positive aspect. This encourages the person to nurture willpower in him/her, to cultivate faith and work on character (overcoming sin). Faith plays an important role in religious life. Only trust in God, His participation in human life is the source of vitality and inspiration. The full realization of the meaning of life, i.e., the association with the Absolute is possible only after death. The finiteness of existence, the experience of one's own mortality plays an important role in acquiring the meaning of life. Death is understood as a part of life, as a transition to a qualitatively different form of life, "eternal life." The peculiarity of religion as a form of spiritual culture is that, perhaps, only it contains the doctrine of the posthumous existence of man. This teaching gives a special flavor to the religious concept of the meaning of life.

The negative aspect of the religious meaning of life is due to the fact that the person experiences the influence of forces that take him/her away from God. This is due to depravity of human nature, "sinfulness". "Avoiding sin" becomes a daily practice, filling life with a special meaning. An important role here is played by the person's understanding of his/her own shortcomings and character defects ("sinfulness"). The religious meaning of life can be defined as "salvation." Man is trying to be saved from sin (a negative aspect) and be saved to perfection, i.e. to God (a positive aspect). Confessional differences within the religious concept of the meaning of life are determined by differences in the understanding of the ways of salvation, the proportion of participation in it of the man and God.

A vivid example of the realization of the religious concept of the meaning of life is presented in the book "Confession" by Augustine Aurelius (354-430) [7]. The text of "Confession" is a dialogue of man with God. What is man's life? It is communication with God and prayer; constant appeal to God, invocation to Him and belittling one's own capabilities. Only the unity with the source of all blessings and perfections, the source of life and love, with God, with eternity fills the life of Augustine with inspiration and meaning.

\section{THE ASCETIC WAY OF LIFE}

Asceticism is restriction, renunciation. Obviously, in itself, the restriction for the sake of restriction does not make sense. People minimize their needs and desires, being guided by some idea. This concept has theological and secular options. The religious asceticism is aimed at limiting daily life for the sake of expanding opportunities for communication with God [8]. In order that God's presence in life be maximum possible, it is necessary to relieve it from attachments, passions, and desires. In this connection, the Apostle Paul says: "Everything is permissible to me, but not everything is beneficial, and nothing should possess me" [9]. In Buddhism, asceticism is understood as the practice of getting rid of desires, necessary for enlightenment. Asceticism is necessary in order to get rid of suffering. This is because desires are the cause of suffering. No desires, no suffering. The meaning of life is the attainment of the state of the Buddha, i.e. enlightenment (Buddha means enlightened).

Non-religious asceticism was successfully practiced in the ancient schools of philosophy. Excesses in all spheres of life corrupt the mind and distort the nature of man, as the Cynics thought. The Philosophical School of Cynics was founded by Antisthenes (445-365 BC), and the most famous representative was Diogenes Sinopski (412-323 BC), the one who "lived in a barrel". According to a legend, Diogenes walked around the streets of Athens in the daylight with a lighted lantern and shouted "I am seeking a man". When Alexander the Great offered him help, in response, the latter asked Alexander to step aside and not obstruct the Sun. History has preserved many legends about how the cynics shocked contemporaries with their extravagant pranks and sayings. They taught that only life in accordance with one's own nature allows one to be free. Social conventions (position in society, social roles, prestige, comfort, luxury, and many others) do not make a person free. An alternative is the "dog way of life" (from the Greek "kinos" - a dog, hence the name of the philosophical school "Cynicism"), because the dog does not need a bowl or mug to drink from the stream. Nature has endowed human being, as well as the dog with everything necessary for happiness and joy. All kinds of pleasure are available to man from nature. The meaning of life is simply to follow nature, and not to complicate life with social conventions and prejudices.

But the rationale for the ascetic meaning of life did not remain in the distant past. "Man is a relative ascetic of life." This thesis belongs to M. Scheler (1874-1928), the founder of philosophical anthropology, one of the influential trends in European philosophy of the twentieth century. Asceticism is a manifestation of man's free will, the essence of which is in the forces of inhibition and disinhibition of the impulses of drives (as opposed to the forces of creativity and creation). M. Scheler believes that the basis of anthropological asceticism is love. In other words, the measure of humanity is determined by the measure of limitations that a person imposes on him/herself. Individual personality is determined by what a person can renounce. Only the human being is able to independently determine the boundaries to $\mathrm{him} /$ herself, to self-limit. This is the freedom of man, and the meaning of his/her life [10].

It should be noted that in the conditions of the consumer society with its inevitable redundancy and lavishness, asceticism is gaining more and more supporters. Thus, minimalism is becoming more and more widespread, a lifestyle that is alternative to the ideology of "consumerism". It is suggested to reduce consumption to a useful minimum. 
The ideologists of the ecological worldview also call for a certain kind of restrictions.

\section{The StOIC MeAning OF LIFE}

Stoicism as a philosophical direction appeared in the Hellenistic-Roman culture. Its founder was Zeno from Kitia in Cyprus (about 333-262 BC), but this direction had a special development and popularity in ancient Rome. Stoicism was the philosophical basis of the state ideology of Rome. Fate is one of the central concepts of the philosophy of stoicism. Following the Logos, i.e. a reasonable pattern of Destiny, is the meaning of the stoic way of life. In following the Logos and Fate, the stoic finds freedom. ("The fate leads the willing but drags the unwilling"). Fate prepares for the man the most unpredictable turns. Life only becomes meaningful only in preserving courage in the face of the most unexpected turns of fate. This is the highest duty and dignity of man. The apparent links of this world, especially social or political, are masks of fate; they do not have power over a free man. Hope and trust in them are meaningless. Only following the duty has a meaning - to accept destiny, to courageously maintain dignity both in wealth and in poverty, in health and in illnesses. Estrangement is a special quality of personality; it allows taking current events and external influences as inevitable and necessary.

Man is unable to change the world, the Cosmos, he is not able to influence the predetermination of fate, but man is able to find peace and freedom in himself. (For the Stoics, Socrates is the model of truly detached behavior. The death of Socrates is an example of realization of the stoic meaning of life). In order to follow fate, it must be cognized. Knowledge plays an important role in the personal life of man. Cognizing necessity and exercising in virtues, the stoic finds inner freedom, which is proclaimed by the Stoics as the highest value.

Stoics paid close attention to the study of passions and subordination them to reason. Passions are the source of evil. There are four kinds of passions: sadness, fear, lust and pleasure. Pleasure was understood as unreasonable use of desires. Pleasures must be avoided by educating impartiality in oneself. Stoic seeks to rise above the passions. This is achieved through the cognition of the essence of good and evil. There is a wide space of the indifferent between good and evil. It is exactly the basis of dignity and courage.

The Roman emperor, commander, and Stoic philosopher Marcus Aurelius Antoine (121-180 AD), in the intervals between the battles, gave himself over to thoughts about the meaning of life. In his work "Reflections", the emperor burdened by affairs complains that he devotes insufficient time to the main care. And the emperor's main concern was to preserve peace in his soul, "to guard the inner genius from reproach and defects" [11].

\section{THE Humanistic MEANING OF LiFE}

Humanism is an ideology that proclaims the human being to be the supreme value. "Personality is the original reality, which is absolute with respect to itself and relative in the series of all others" [12]. The human being him/herself is the creator of the meaning of his/her life, and hence the creator of his/her destiny. To create destiny based on one's abilities and talents is the higher meaning of human life. Humanists proceed from the premise that each person has talents, which only need to be discovered and developed.

Humanism declares the inherent value of the man's personality, and his right to free development and selfexpression. The development and realization of abilities and talents presuppose a whole set of knowledge and skills that the person masters in society and through society. Therefore, the humanistic meaning of life assigns particular value to actions aimed at serving the society. To be in demand, necessary, useful for people is an important part of the life program, without which the fullness of life, satisfaction with life is impossible. The quality of life is largely determined by the measure of the demand for a person by the society. The experience of one's life as a necessary part of the whole gives meaning to individual existence: "The meaning of my life is in itself, and in what I will help the lives of others; also my immortality is in that the world will not die with me and I can also contribute to it" [13].

Philosophical criticism has repeatedly pointed out that the absolute form of the value of the human being leads to serious difficulties of existential, social, ecological, and legal nature [14]. But, in spite of this, the humanistic life program remains an important factor of social development. Since the 20th century, the ideas of humanism are complemented by the notion of a favorable environment for human health and development; the concept of "planetary humanism" is being developed [15]. Habitat is an important factor in life and it needs care from human beings. Moreover, every manifestation of life needs care and respect. In this way, there arise the principle of "reverence for life" by Albert Schweitzer (1875-1965) and the principle of rational human responsibility for the nature by V.I. Vernadsky (1863-1945). They are an important complement to the humanistic life program.

\section{HEDONISM AND EUDEMONISM}

In the concept of hedonism, the meaning of life is determined by the desire to achieve pleasure and enjoyment; pleasure is the basic value, the quality of life. Hedonism is a very ancient concept. It was already the ancient philosophical school of Cyrenaics, founded by Aristippus (435-356 BC) that disseminated the doctrine that the highest value is not the possession of things and goods but the enjoyment of things and goods. Pleasure as the enjoyment of the moment of the present is the main motive of all human actions. It makes sense only that which brings pleasure. Life without pleasure has no meaning. However, Cyrenaics also discovered the paradox of hedonism. On one hand, reliance on pleasure as the highest good protects the distinctiveness and self-worth of the individual; whereas, on the other hand, hedonism becomes the basis for moral debauchery, antisocial behavior, and egocentrism.

The idea of pleasure as the meaning of life has its development in epicureanism. Epicurus (341-270 BC) 
developed a classification of pleasures, dividing them into several groups. Not all kinds of pleasure, according to Epicurus, are true, because for most of them one has to pay with suffering. Sensual or bodily pleasures lead to suffering, as well as pleasure from the possession of knowledge and skills. And only one kind of pleasure is called authentic by Epicurus. It is a pleasure from the communication with friends. Unselfish relations and friendly conversation, clarifying abstract concepts gives pleasure, which is followed by neither physical nor mental suffering. Ataraxia is a sublime state of the soul, serenity, peace of mind. Achieving ataraxia, as the highest good, is the meaning of life. Pleasure as the absence of suffering is called happiness by Epicurus; hence the name of the doctrine - "eudemonism." Hedonism and eudemonism in fact have a common basis - the desire for pleasure.

Later on, it was convincingly shown by philosophy that pleasure cannot be a universal principle for the formation of social relations and moral behavior. Pleasure is an accompanying effect for those actions that are considered as successful (utilitarianism). Pleasure and suffering are the functions of social relations (Marxism). For example, a prominent representative of existential psychology, V. Frankl (1905-1997) emphasized that happiness cannot be an object of aspiration. One has to have a reason to "be happy". Happiness arises as a result of realization of that meaning, which is hidden, potentially present in the current life situation. "Excessive striving" for enjoyment and happiness becomes the cause of suffering and unhappiness. If a person finds the meaning of his/her life, it brings him/her not only happiness, but also the ability to cope with suffering [16].

At the level of public consciousness, hedonism remains one of the leading concepts of the meaning of life.

\section{The DeOntologicAl MEANING OF LIFE}

Deontology is the direction of philosophy, in the center of which is the notion of duty. In the most general definition, duty is a voluntarily accepted obligation. As a duty, there may be considered the birth and upbringing of children, service to the Motherland, one's own people, struggle against terrorism, protection of the environment, etc.

The concept of duty assumes the greatest significance in the philosophy of I. Kant (1724-1804). According to Kant, duty is an objective principle, it is prescribed to the mankind as such. Human being is first and foremost a moral being. Based on the demand of duty, a person is realized precisely as a person, as a moral being. The knowledge about duty is presented by I. Kant in the form of a categorical imperative the formula of the moral law. The categorical imperative prescribes actions that are good in themselves, objectively without taking into account the consequences, irrespective of any purpose. "Act only according to such a maxim, guided by which you, at the same time, can wish that it became a universal law"; or "Act in such a way that you always treat humanity both in your own person and in the person of everyone else as your goal and never treat only as a means" [17]. The notion of duty is formalized both as knowledge and as a specific experience. I. Kant calls it respect. Respect is a feeling that is inseparably connected with reason. Through respect, a person affirms the dignity of another person. The need for action out of respect for the moral law is called duty by I. Kant. "Duty is respect for the right of another." Debt is a subjective principle of morality. It means that the moral law itself becomes the motive of human behavior. The sphere of morality is the sphere of practical realization of human freedom.

Sometimes Kant's ethics is called rigoristic. Rigorism in the general sense is strictness and uncompromisingness in following principles and life beliefs. Many religious and philosophical teachings are rigoristic in their essence. Such commitment to principle is explained by the fact that only principles and beliefs fill a person with spiritual content and radically distinguish a person's life from the life of an animal. A person's life loses its meaning when he/she allows a deviation from such imperatives. I. Kant believed that to be a human being is to follow a duty. The meaning of individual human life is determined by following a duty.

\section{CONCLUSION}

The meaning of life is exclusively a human phenomenon. No living being, except for the human being, has surpassed the physical capabilities. Only human being needs suprabiological forms of substantiating his/her own life program. "The meaning is originated from a thought; that is, to live with a thought which is quite fundamental, deep, penetrating all human aspirations and hopes. The need for the meaning of life is the need for the integrity of the life experience of human being, for bringing him/her to some value-based, ideal unity" [18]. The meaning of life exists by constant comprehension, reflection on how and by what we live. It is impossible to keep the meaning of life once and for all. It is equally impossible to live by a single meaning all one's life. To keep oneself in the meaning or reorient to other meanings requires serious efforts. The property of meaning to lose its significance gives the problem of the meaning of life a constant acuteness.

In the meaning of life, there are expressed in a concentrated way the person him/herself, his/her essence, nature, which is a combination of three components - biological, social and spiritual. Therefore, conventionally the concepts of the meaning of life can be divided into three groups.

Ontological models provide an understanding of the special quality of Being - "Being-in-the-meaning", which under certain conditions is revealed to man. The meaning of life is acquired only through participation in the Being-in-the-meaning.

Humanistic models suggest that there is no meaning in life in itself. The meaning is formed and brought into life by the person him/herself. It is the basic choice by which a person defines him/herself, his/her life. In case of difficulty with the adoption of the meaning of life, it can be corrected. Human life is seen here as a meaning-forming creative process.

Sociobiological model suggests that meanings are embedded in the very nature of human being. Meanings are due to the long process of biological evolution of the species. Human being is the bearer of meaning. Here, the vital task is 
described as the cognition of one's own nature, character, and the construction of the corresponding model of behavior [19].

The solution of the problem of the meaning of life is directly connected with the organization of the social space of the human being, the process of the society's consolidation and reproduction of itself. "The problem of the meaning of life is real only where the question about the integrity of life is posed, about the relation between its beginning and end, and thus - about what is after life. In other words, the phenomenon of the meaning of life exists only for a person who has set out to understand his/her behavior, his/her line of life. The meaning of life is not only its understanding, but also self-justification. 'Bare existence' is not self-sufficient; it does not satisfy the human being" [20]. At the same time, in modern culture the adoption of the "meaning of life" is significantly hindered by the widespread use of addictive forms of behavior. The addictive personality loses the ability to form and perceive the "meaning of life."

Thus, the meaning of life is the most profound or the main motive of our existence. As a philosophical problem, the meaning of life is the conviction that "life is worth living", that each fragment of life deserves a respectful and responsible attitude. It is through such an attentive and thoughtful attitude to every action that life reveals its meaning [20].

\section{REFERENCES}

[1] E.A. Bryun, A.V. Tsvetkov, Practical psychology of dependence. Moscow, 2014, pp. 172-173.

[2] Science and quasi-science. Moscow, 2008.

[3] S.A. Lokhov, Worldview as an object of philosophical reflection // Bulletin of the Peoples' Friendship University, series Philosophy, 2003, No. 1 (9), pp. 29-37.

[4] Albert Camus, Myth about Sisyphus // Twilight of the Gods. Moscow, 1989.

[5] P.K. Grechko, The meaning of life - where is it?//Social studies: manual for applicants. M.,2009, pp. 347-359.

[6] F.M. Dostoevsky, Notes from the underground, part I, Underground, Ch. VII., St. Petersburg, 2008, pp. 62-68.

[7] Saint Augustine of Hippo, Confessions. Harmonds worth Middles ex, England: Penguin Books. 1961.

[8] Rene Descartes, Discourse on the Method of Rightly Conducting One's Reason and of Seeking Truth//, M., 1989.

[9] Holy Bible. Corinthians 6:12

[10] M. Scheler, Forms of knowledge and education // Selected works. Moscow, 1994, p. 30.

[11] Marcus Aurelius, Meditations. Moscow, 2008, p. 45.

[12] A.N. Pavlenko, Lectures on Dostoevsky. St. Petersburg, 2016, p. 104.

[13] Modern Humanism: Documents and Research. / / Special issue of the quarterly journal "Common sense. Journal of skeptics, optimists and humanists". Moscow, 2000, p. 122.

[14] A.N. Pavlenko, Lectures on Dostoevsky. St. Petersburg., 2016, pp. 27-38.

[15] Modern Humanism: Documents and Research. // Special issue of the quarterly journal "Common sense. Journal of skeptics, optimists and humanists". Moscow, 2000, p. 28.

[16] V. Frankl, The Doctor and the Soul: Logotherapy and Existential Analysis. Moscow, 2017, pp. 62-68.

[17] I. Kant, Critique of Practical Reason // Kant I. Works: in 4 vol., part 1, Moscow, 1965, p. 260.
[18] P.K. Grechko, The meaning of life - where is it?//Social studies: manual for applicants. M., 2009, p. 359.

[19] Edward O. Wilson, The meaning of human existence, New York. London, 2014

[20] P.K. Grechko, The meaning of life - where is it?//Social studies: manual for applicants. M.,2009, p. 355. 